\title{
The effect of powder characteristics on pressure sensitivity of powder injection moulding compounds
}

\author{
Berenika Hausnerova ${ }^{a} *$, Tomas Sedlaček ${ }^{a}$, Petr Filip ${ }^{b}$, Petr Saha $^{a}$ \\ ${ }^{a}$ Tomas Bata University in Zlin, Faculty of Technology, Polymer Centre, TGM 275, 76272 Zlin, Czech Republic ${ }^{\mathrm{b}}$ The Institute of Hydrodynamics of the Academy of Sciences of the Czech \\ Republic, Pod Patankou 5, 16612 Prague, Czech Republic
}

\begin{abstract}
A B S T R A C T
Pressure effect on the rheological behaviour of powder-polymer compounds intended for powder injection moulding was determined. A single-piston capillary rheometer modified by addition of a second chamber with a restricting needle valve generating backpressure increasing the pressure in the melted material during the flow through the die was employed to determine pressure sensitivity coefficients. The results obtained for three compounds varying in the characteristics of powders used confirmed that compounds at the loading level close to the maximum packing are more sensitive to pressure than polymer binder. It is shown that pressure sensitivity coefficients of these materials are strongly dependent on powder characteristics particle size and particle size distribution. The highest coefficient $\left(32.9 \mathrm{GPa}^{-1}\right)$ was found for compound containing broad particle size distributed powder having a perceptible portion of small particles.
\end{abstract}

\section{Introduction}

Development of powder technologies including process simulations can only be reached when the material and processing parameters are known with sufficient accuracy. In case of injection moulding of metallic and ceramic powders (powder injection moulding - PIM) a factor disregarded is the influence of pressure on the flow behaviour of feedstocks though pressure might alter viscosity significantly.

PIM compounds during injection moulding step represent the concept of multicomponent systems whose reliable rheological model was presented recently by the research group connected to German, e.g. [1].

Techniques to obtain pressure-dependent viscosity data can be adopted from polymer processing, where a lot of effort has been put to this subject starting with Barus [2] in 1891. A brief outline is given in Fig. 1. This summary implies that the scientific attention concerning pressureaffected flow characteristics has been entirely paid to pure polymer melts. For PIM materials German [20] stated that sensitivity to pressure should decrease with the loading level of powder. This was confirmed for the low to moderate (up to 30vol.\%) powder loadings in our previous paper [21]. Nevertheless, at higher loading levels (flow complicated by the onset of instabilities) sensitivity to pressure seems to be enhanced comparing to a pure polymer binder [22]. In order to confirm this idea the following contribution examines three types of compounds differing in the powder characteristics, whose flow is stable in the broad range of shear rates.

\section{Experimental}

\subsection{Materials}

The powders used in the experiments are composites of tungsten carbide and cobalt (cemented carbides) supplied by Sylvania Tungsten, Czech Republic. The metallic component (cobalt), which only constitutes a minor proportion of the carbide mixture, serves as the matrix for the final sintered part. Three grades were tested, differing in their particle size distribution - BC10U, BC37S, and BC55S. The average density amounts to $14.90 \mathrm{gem}^{-3}$ for $\mathrm{BC} 10 \mathrm{U}$ and $14.94 \mathrm{gem}^{-3}$ forBC37S and BC55S. As can be seen on the SEM image of BC10U as an example (Fig. 2 ), the shape of the particles was irregular with a relatively broad particle size distribution.

The polymer binder (Table 1) was based on LDPE Lacqtene $1200 \mathrm{MN}$ 8 (Atochem), and paraffin, in addition to ethylene-aciylic acid block copolymer Ex 225 (Exxon) serving as a steric stabilisator of the feedstock.

\subsection{Blending procedure}

The compounds were prepared in a laboratory kneader (Brabender Plasticorder PL-2000-6, mixer type W 50E) at $150{ }^{\circ} \mathrm{C}$ and $80 \mathrm{rpm}$. The mixing chamber was filled by $70-80 \%$ of its volume. Firstly, a small portion (1/5) of the polymer binder was preheated in the mixer. Then, 


\begin{tabular}{|c|c|c|c|c|}
\hline Author(g) & Experimental device & Matcrial & $\begin{array}{l}\text { Pressure } \\
\text { ronge }\end{array}$ & Cumiments \\
\hline Laurt [3! & ilit-dic theometer & hiph molecular meght LDPE & $\begin{array}{l}\text { gistocifirce up } \\
\text { to } 2.10^{4} \mathrm{~N}\end{array}$ & 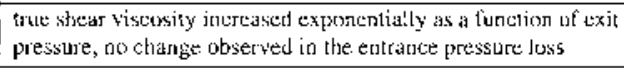 \\
\hline Dristorl] and Bogute [A] & $\begin{array}{l}\text { barrel-ilowritreaum } \\
\text { chatuber-qulye }\end{array}$ & polystymene & Lp to $124 \mathrm{MP} 4$ & 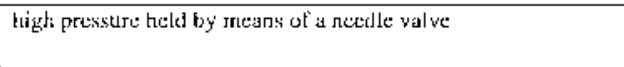 \\
\hline $\begin{array}{l}\text { Kudijk and warl den } \\
\text { Bnile [5] }\end{array}$ & $\begin{array}{l}\text { twi-piston slit } \\
\text { itueoneter }\end{array}$ & 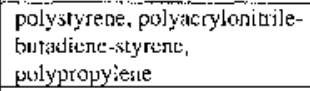 & up to $[60 \mathrm{MPu}$ & 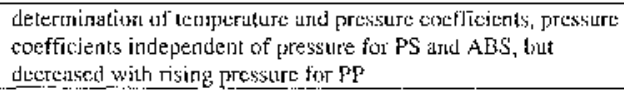 \\
\hline Moldonaters et ai [6] & 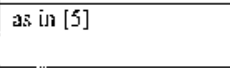 & thermislropic coprofyestars & up to $8 0 \longdiv { \mathrm { MPa } }$ & 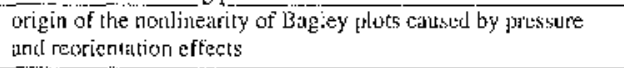 \\
\hline Hath [?] & & & & 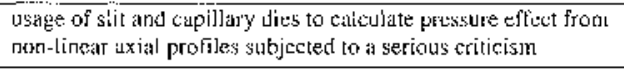 \\
\hline Malckley et al. [8] & $\begin{array}{l}\text { Inulti-puns fuetmeter, } \\
\text { in principle similar to } \\
\text { that of hestover |9| }\end{array}$ & $\begin{array}{l}\text { silicon oil, } 5 \text { and } 20 \mathrm{wt} \% \\
\text { solutiuns of pulyisobutylene } \\
\text { in Letulisi }\end{array}$ & $\mathrm{upto} 21 \mathrm{MF}$ & 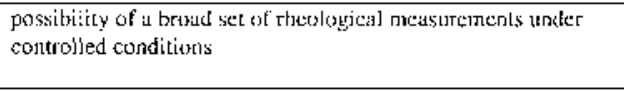 \\
\hline $\begin{array}{l}\text { Maktey and Spineler } \\
\text { [lo] }\end{array}$ & ais in $[8 \mid$ & L.L.PPE & lip to $23 \mathrm{MPa}$ & 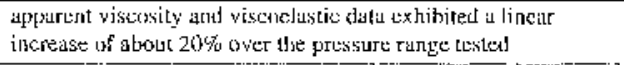 \\
\hline $\begin{array}{l}\text { Pinding at al. [1 [, 12], } \\
\text { Coudb und Binding } \\
{[13]}\end{array}$ & $\begin{array}{l}\text { bare]-dowistrectm } \\
\text { chamber-valve }\end{array}$ & $\begin{array}{l}\text { pulystyrene, PMMA, } \\
\text { polypropylene, LDPE, IIDPIi }\end{array}$ & นए (0) 80 M & 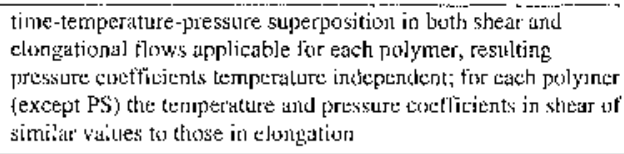 \\
\hline Goubert $[1 / 4]$ & 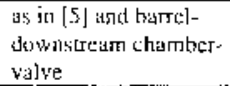 & LLDPE & up to $920 \mathrm{MPa}$ & 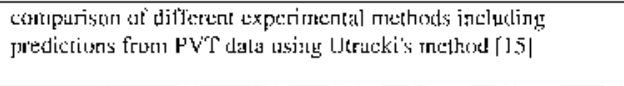 \\
\hline $\begin{array}{l}\text { Kuran and Joaly [16], } \\
\text { Park :Ind Deady [17] }\end{array}$ & $\begin{array}{l}\text { ligh-plessuce sliulitg } \\
\text { platc rheoneter }\end{array}$ & LLLPE & ир $70 \mathrm{MP}$ & 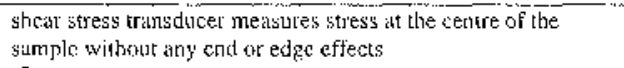 \\
\hline Cameras et ill $[18]$ & $\begin{array}{l}\text { bariel-downstrenII } \\
\text { chamber-wsilve }\end{array}$ & 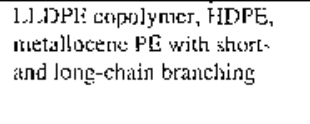 & LIp to 50 MFil & 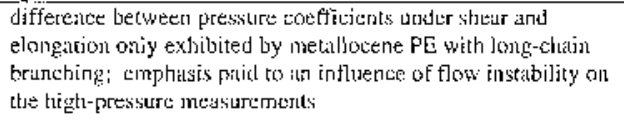 \\
\hline Cirdisugests et al. [ 19$]$ & $\begin{array}{l}\text { DatTel-dowjstreani } \\
\text { charnter-vilwe }\end{array}$ & 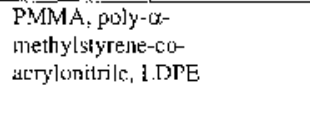 & u $1070 \mathrm{PHP}_{\mathrm{i}}$ & 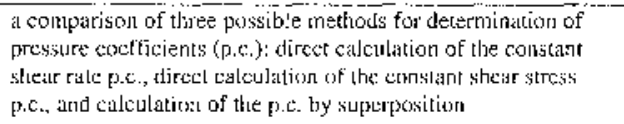 \\
\hline
\end{tabular}

Fig. 1. A brief outline of experimental and theoretical works on pressure-dependent viscosity [3-19],

the powder and remaining binder were added by turns during the first minute and the suspension was mixed for about 5 more minutes.

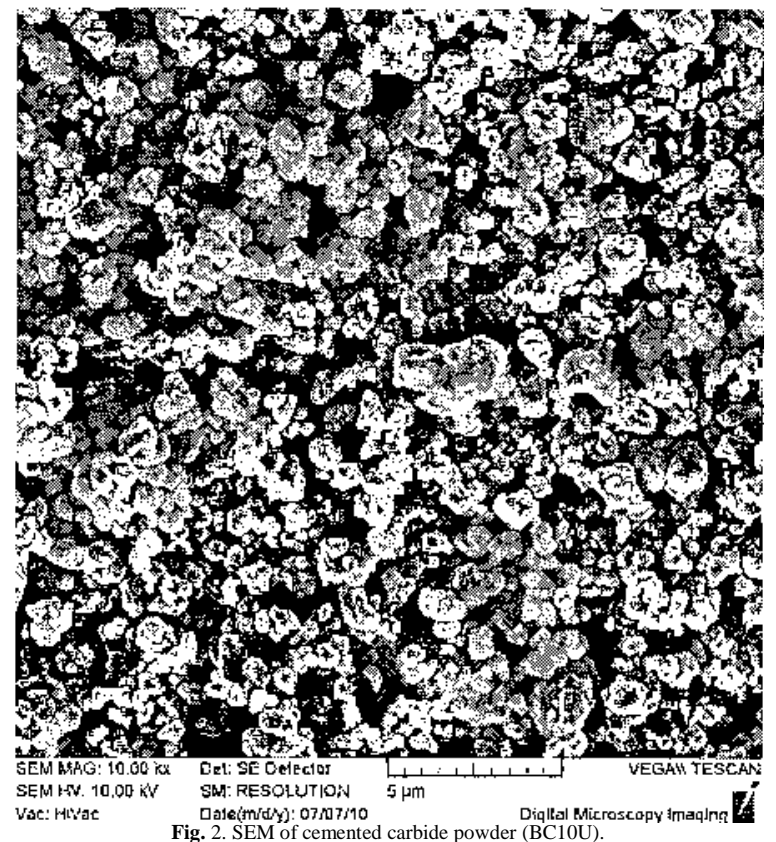

The kneader torque was always constant over the last 2-3 min indicating that the dispersion process had been completed.

Density of 50 vol.\% feedstocks was measured on injection moulded samples (MINIMAX MOLDER CS-183 MMX, Custom Scientific Instruments, Inc., USA). Prepared samples in volumes about $2.55 \mathrm{~cm}^{3}$ were used for density determination via Archimedes method in three different liquids: distillated water $\left(1.000 \mathrm{~g} / \mathrm{cm}^{3}\right)$, methyl alcohol $\left(0.792 \mathrm{~g} / \mathrm{cm}^{3}\right)$ and hexane $\left(0.659 \mathrm{~g} / \mathrm{cm}^{3}\right)$. The experiments reveal the values: $8.073 \pm 0.003 \mathrm{~g} / \mathrm{cm}^{3}$ for BC10U feedstock, $8.123 \pm 0.012 \mathrm{~g} / \mathrm{cm}^{3}$ for BC37S, and finally $8.245 \pm 0.002$ $\mathrm{g} / \mathrm{cm}^{3}$ for BC55S.

\subsection{Methods}

The rheological behaviour of the compounds was studied in a capillary rheometer (Gottfert 2001) with a plane $\left(180^{\circ}\right)$ capillary entrance at $150{ }^{\circ} \mathrm{C}$. As introduced by Sedlacek et al. [23], and described in detail in our previous paper [22], the rheometer was modified with an additional device generating backpressure, which causes increase of pressure actuating on the tested materials, Fig. 3. It consists of a chamber with restricting needle valve moving horizontally by means of screw thread in order to set the level of pressurization applied on the material during its flow through the die.

The pressure values were taken at two points: in the reservoir closely upstream from the entrance to the capillary (entrance pressure), and in the second chamber (backpressure). Experiments were done with two capillaries: long $(\mathrm{L} / \mathrm{D}=20 / \mathrm{l})$ and orifice $(\mathrm{L} / \mathrm{D}=0.12 / 1)$. Pressure- dependent viscosity was measured at different values of backpressure in the shear rate range from 80 to $5000 \mathrm{~s}^{-1}$. The true values of shear 
Table 1

\begin{tabular}{|c|c|c|c|}
\hline Malerjal & Density [I $\mathrm{cm}^{-3} \mid$ & Melting paint |“ C] & Gontent [wt'k] \\
\hline ].DTE & 0.918 & 107 & 53 \\
\hline EM & 0.929 & 100 & 21 \\
\hline Paraffin wax & 0.900 & $5 n$ & 26 \\
\hline
\end{tabular}

stress, shear rate, and shear viscosity were calculated applying Rabinowitsch and Bagley corrections.

The Carreau-Yasuda model [24] was employed for fitting the measured temperature and pressure-dependent shear viscosity

$r(y)-\frac{T_{i n} f(P: T)}{\left[1+\left(K_{1} \int(P: T \Gamma)^{0}\right]^{-\frac{1}{2}}\right.}$

where $r\left(y j\right.$ represents the shear rate-dependent viscosity, $\left.\mathrm{r}\right|_{0}$ stands for the zero-shear viscosity, 7 is the shear rate, $\mathrm{K}_{\mathrm{lf}} n$, and $a$ are the empirical constants; a function/(P,T) takes into account an influence of pressure and temperature.

For the determination of temperature sensitivity coefficient of viscosity $a$ the Arrhenius-type exponential expression - widely used in polymer engineering calculations and modelling of non-isothermal injection moulding flows - was chosen

$f-e^{-\left(k+T^{2}\right)}$

where $T$ and $T_{r}$ are the testing and reference temperatures, respectively. The pressure effect was determined utilizing the exponential relation in a form (see e.g. Barus [2])

$f-e^{i p}$

where $\mathrm{jB}$ is the pressure coefficient of viscosity, and $\mathrm{P}$ stands for the gauge pressure.

\section{Results and discussion}

The pressure sensitivity of the PIM compounds at the filling level close to the maximum were examined for three cemented carbides differing in their particle size distributions as documented in Fig. 4.

The pressure-dependent viscosity data for their 50vol. $\%$ compounds with polymeric binder are shown in Figs. 5-7; the solid lines represent data fitting by the Carreau-Yasuda model the parameters of which for the individual powders are summarized in Table 2. The Nahme number relating temperature rise due to viscous heating and temperature change necessary to alter the viscosity was taken into account, for detailed analysis see Carreras et al. [18].

Generally, PIM compounds show high sensitivity to variations in shear rate, even if the behaviour of a polymer binder approaches a Newtonian course. This trend is progressively pronounced with an increase of powder concentration. Depending on the type of the dispersed particles,: particularly on their particle sizes, a yield point may appear at a low shear rate. At higher shear rates, however, this structure is broken and the viscosity is dominated by hydrodynamic interactions. Shear thinning behaviour indicates particle and polymer orientation and ordering with flow.

The shape of the particle size distribution curve determines basic viscosity behaviour. The powder BC10U containing the highest portion of small particles (mean diameter around $1 \mathrm{jjm}$ ) exhibits lower non-Newtonian index than BC37S and BC55S based compounds (mean diameter 5-7 jjm). Zero-shear viscosity 170 evaluated from the Carreau-Yasuda model is higher for BC10U comparing to the other two compounds as can be seen from Table 2. This behaviour may be attributed to the enhanced inter-particle friction of the small particles due to their surface area.

Concerning the effect of pressure, regardless of powder characteristic it is clear that the pressure coefficients of PIM compounds are not monotonously decreasing function of the powder content. In accordance with the literature concerning PIM compounds [20], the compounds are less sensitive to pressure than the polymer binder at low to moderate loading level (up to 30vol.\%) as shown in our

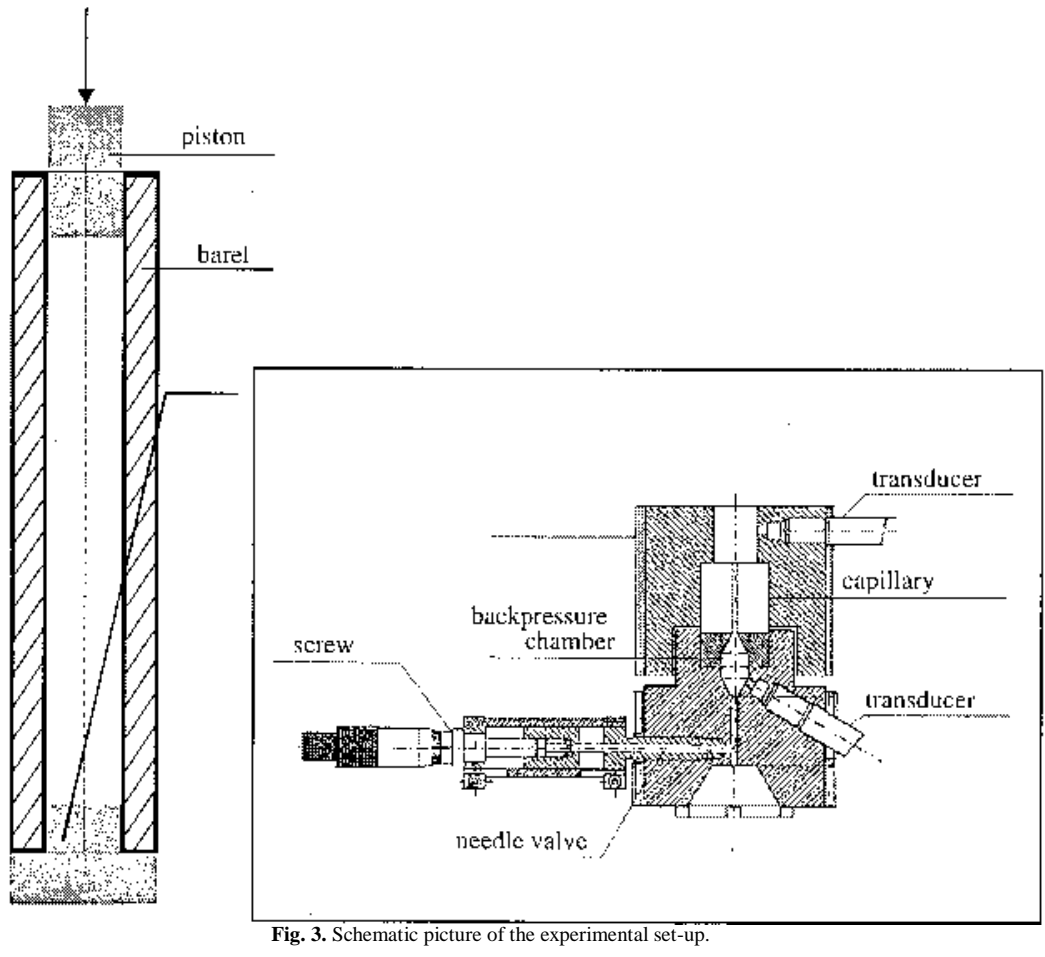


previous paper [21 ]. At higher loading, i.e. closer to maximum packing fraction, the pressure sensitivity obtained for compounds based on the three different powders (see Table 2) is enhanced in a comparison to the pure polymer binder, for which a coefficient $j \mathrm{~B}=16.4 \mathrm{GPa}^{-1}$ is lower than each coefficient $\mathrm{jB}$ in Table 2 (reference temperature $T_{r}=150^{\circ} \mathrm{C}$ ).
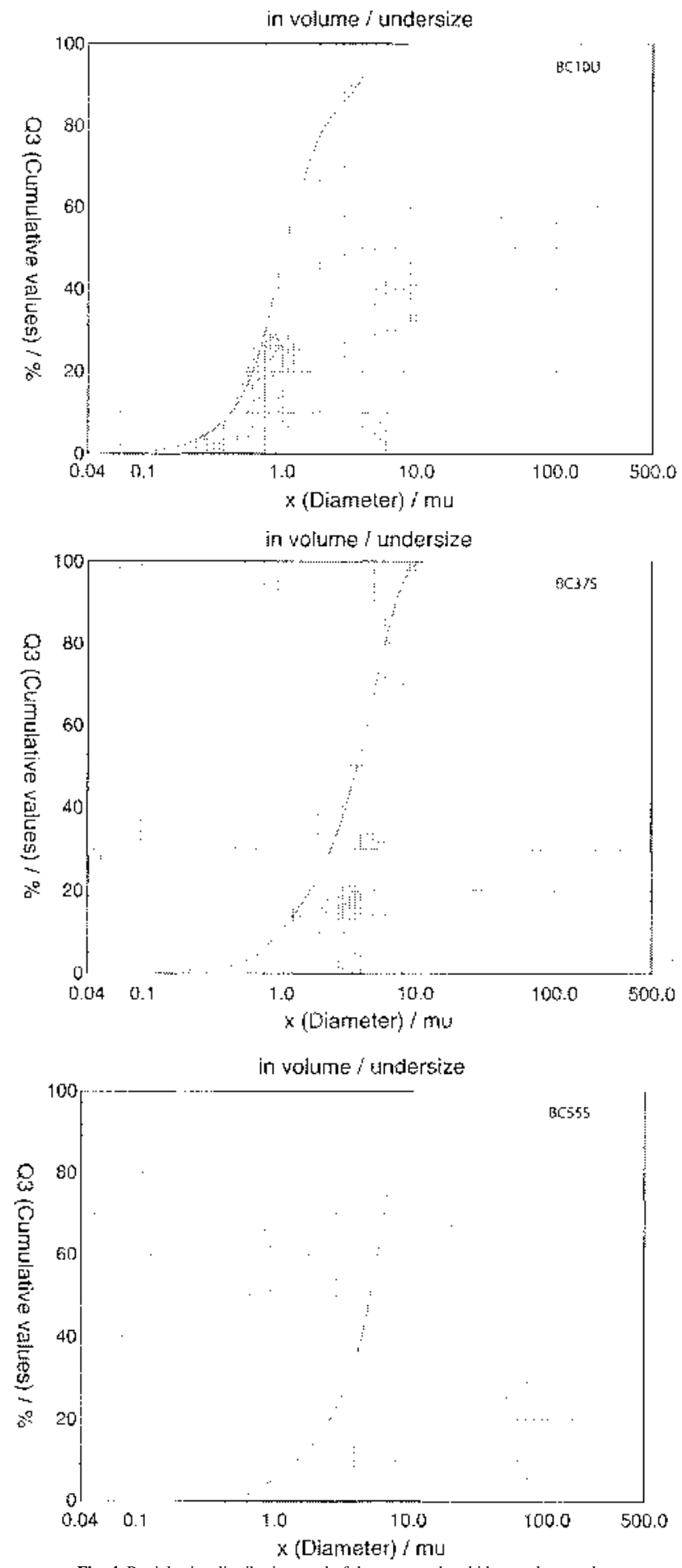

Fig. 4. Particle size distributions and of the cemented carbide powders used.

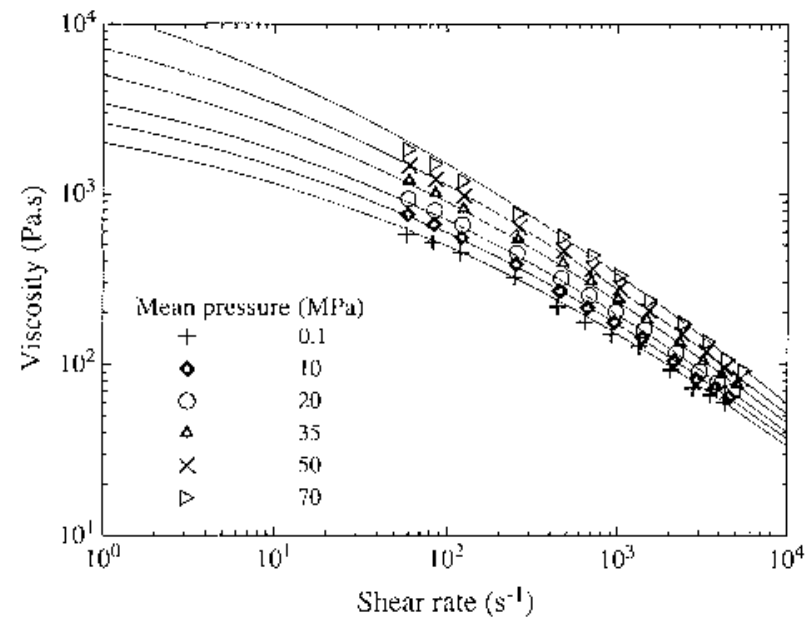

ig. 5. Pressure-dependent viscosity vs. shear rate curves for 50 valch

Furthermore, the sensitivity of the PIM compounds to pressure might be altered via tailoring of filler characteristics. The pressure sensitivity coefficients of the particular powders are ordered in the following way: BC10U>BC37S $>$ BC55S. The highest $\mathrm{j} 3$ coefficient $\left(32.9 \mathrm{GPa}{ }^{* 1}\right)$ is found for compounds containing broader particle size distributed powder having a perceptible portion of small particles, whereas the pressure coefficients j8's of the other two powders are rather similar $\left(19.25 \mathrm{GPa}^{-1}\right.$ for $\mathrm{BC} 37 \mathrm{~S}$ and 18.30 $\mathrm{GPa}^{-1}$ for BC55S).

The mechanism of pressure effect on viscosity is still unclear even for pure polymers. The results obtained for PIM compounds imply the coexistence of the two mechanisms. First, at low to moderate loading levels the pressure sensitivity of the compounds is governed by the sensitivity of the polymer binder component, which is connected to free volume changes as recently shown by Sedlaček et al. [25], and diminishes as powder concentration increases. Second, at high powder loading the driving factor is compressibility of powder itself related to the (re)organization of the particles within the melt during pressurization.

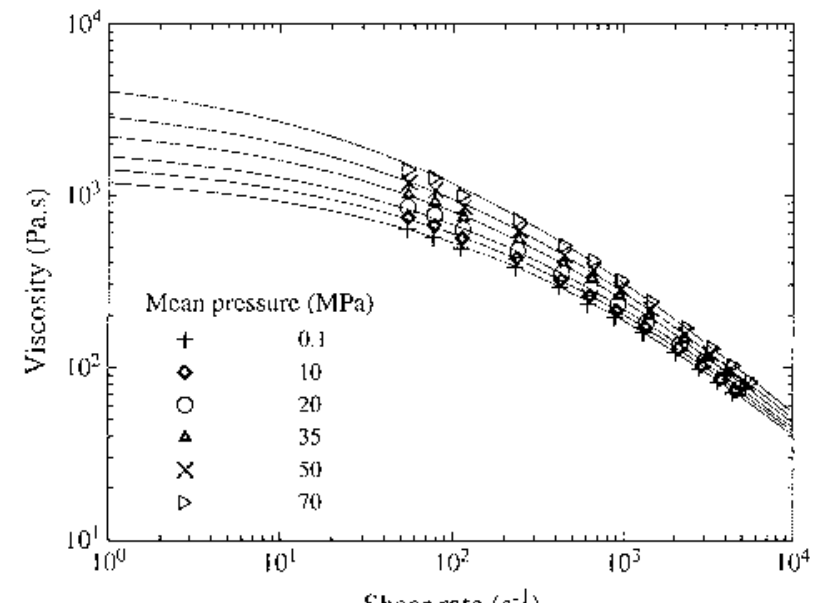

Shear rate $\left(s^{-1}\right)$

Fig. 6. Pressure-dependent viscosity vs. shear rate curves for 50 vol.\% BC37S carbide powder compound (parameters of the Carreau-Yasuda model given in Table 2). 


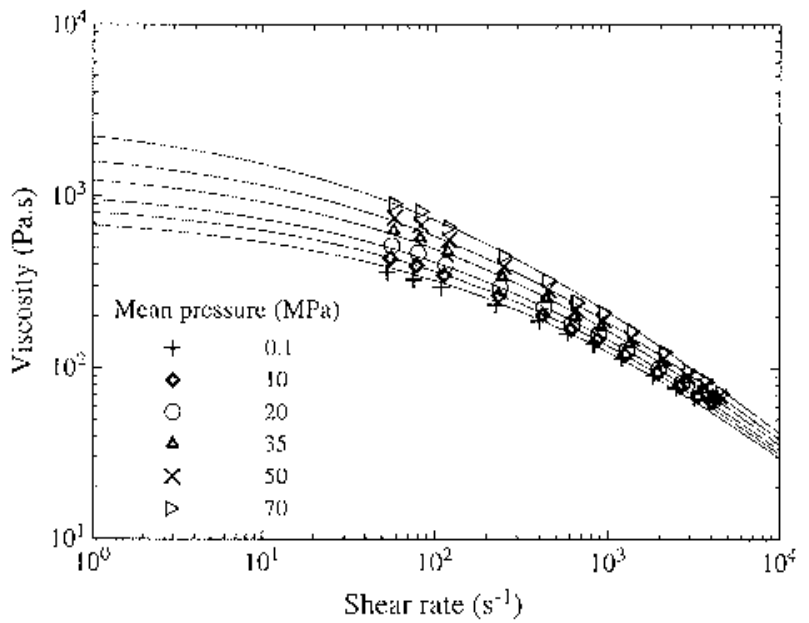

Fig. 7. Pressure-dependent viscosity vs. shear rate curves for 50 vol.\% BC55S carbide powder compound (parameters of the Carreau-Yasuda model given in Table 2).

Table 2

Pressure sensitivity coefficients and parameters of the Carreau-Yasuda model for BC10U, BC37S, and BC55S carbide powder compounds.

\begin{tabular}{|c|c|c|c|c|c|c|}
\hline Material & {$\left[1 / \mathrm{CH}^{\mu} \mathrm{A}\right]$} & $r_{\mathrm{a}}\left[\mathrm{P}_{\mathrm{a}} \mathrm{l} \mathrm{s}\right]$ & $\pi$ & $\left.\left.\mathrm{T}_{r}\right|^{\mathrm{N}} \mathrm{C}\right]$ & $k_{1} 10^{-1}[5]$ & a \\
\hline BCLOU & 32.96 & 4051.7 & 0.10 & 0 & 8.932 & 0.289 \\
\hline $\mathrm{BC} 7 \mathrm{~s}$ & 10.25 & $1,373,8$ & 0.10 & 0 & 3.226 & 0.444 \\
\hline BC555 & 18,30 & 787.7 & 0.10 & 0 & $2: 548$ & 0,435 \\
\hline
\end{tabular}

\section{Conclusion}

The influence of pressure on shear flow of cemented carbide powder based PIM compounds was studied using a backpressure modified single-piston capillary rheometer.

The pressure coefficients of PIM compounds are not monotonously decreasing function of the powder content. The pressure sensitivity of the PIM compounds becomes reduced as the amount of carbide powder in the compound rises to a moderate level (up to 30 vol.\%), while highly filled systems (tested on 50vol.\%) exhibit stronger pressure sensitivity than a corresponding pure polymer binder. A comparison of the results obtained for three different powder based compounds proved a strong effect of the particle size distribution, and especially portion of small particles, on pressuredependent flow behaviour. This implies that pressure sensitivity of the PIM compounds can be altered by modifying filler characteristics. The mechanism will be further investigated in a connection with pressure-volume-temperature characteristics.

\section{Acknowledgments}

This work has been financially supported by the Grant Agency of the Czech Republic (Project No. 103/08/1307) and the Ministry of Education, Youth and Sports of the Czech Republic (Project No. MSM 7088352101). B.H. is the laureate of the national section "For Women in Science", being financially supported by L'Oreal during the year 2007.

\section{References}

[1] S. Ahn, S.J. Park, S. Lee, S.V. Atre, R.M. German, Powder Technol. 193 (2009) 162-169.

[2] C.J. Barus, Proc. Am. Acad. 27 (1891) 13-19.

[3] H.M. Laun, Rheol. Acta 22 (1983) 171-185.

[4] P.D. Driscoll, D.C. Bogue, J. Appl. Polym. Sei. 39 (1990) 1755-1768.

[5] S.E. Kadijk, B.H.A.A. van den Brule, Polym. Eng. Sei. 34 (1994) 1535-1546.

[6] P. Moldenaers, J. Vermant, J. Mewis, 1. Heynderickx, J. Rheol. 40 (1996) 203-219.

[7] CD. Han, Polym. Eng. Sei. 48 (2008) 1126-1140.

[8] M.R. Mackley, R.T.J. Marshal, J.B.A.R. Smeulders.J. Rheol. 39 (1995) 1293-1309.
[9] R.C. Westover, Polym. Eng. Sei. 6 (1966) 83-89.

[10] M.R. Mackley, P.H.J. Spitteler, Rheol. Acta 35 (1996) 202-209.

11] D.M. Binding, M.A. Couch, K. Walters, J. Non-Newt. Fluid Mech. 79 (1998) 137-155.

[12] D.M. Binding, M.A Couch, K. Walters, J. Non-Newt, Huid Mech. 87 (1999) 155-164.

[13] M.A. Couch, D.M. Binding, Polymer 41 (2000) 6323-6334.

[14] A Goubert,J. Vermant, P. Moldenaers, A Göttfert, B. Ernst, App. Rheol. 11 (2001) 26-37.

[15] L.A. Utracki, Polym. Eng. Sei. 25 (1985) 655-668.

[16] F. Koran, J.M. Dealy, J. Rheol. 43 (1999) 1279-1290

[17] H.E. Park, J.M. Dealy, Macromolecules 29 (2006) 5438-5452.

[18] E.S. Carreras, N. El Kissi.J.M. Piau, F.Toussaint, S. Nigen, Rheol. Acta 45 (2006) 209-222.

[19] R. Cardinaels, P. Van Puyvelde, P. Moldenaers, Rheol. Acta 46 (2007) 495-505.

[20] R.M. German, Powder Injection Moulding, MPIF, Princeton, New Jersey, 1995.

[21] B. Hausnerova, T. Sedlacek, R. Slezak, P. Saha, Rheol. Acta 45 (2006) 290-296.

[22] B. Hausnerova, T. Sedlacek, P. Vltavska, Powder Technol. 194 (2009) 192-196.

[23] T. Sedlacek, M. Zatloukal, P. Filip, P. Saha, A. Boldizar, Polym. Eng. Sei. 44 (2004) 13281337.

[24] K. Yasuda, R.C. Armstrong, R.E. Cohen, Rheol. Acta 20 (1981) 163-178.

[25] T. Sedlacek, R. Cermak, B. Hausnerova, M. Zatloukal, A. Boldizar, P. Saha, Int. Polym. Proc. 20 (2005) 286-295. 